\title{
Integration of a Computer Device for Learning and Training Situations: The Case of Faculty of Sciences Ben M'sik (FSBM)
}

\author{
https://doi.org/10.3991/ijet.v14i03.9355 \\ Mohssine Bentaib( $\left.{ }^{\bowtie}\right)$, Mohammed Talbi, Bouzekri Touri \\ University Hassan II of Casablanca, Casablanca, Morocco \\ mohssine.bentaibeunivh2c.ma
}

\begin{abstract}
Education and distance education often provide answers to several issues related to the transmission of knowledge, its design and acquisition. However, these virtual learning environments do not meet with the same degree of satisfaction for all users, it is probably imperative to decide on the methodology of integrating transmission order size ergonomic, aesthetic, practical, time relating all shared a concern, which is the consideration of the student user of these new technologies in order to develop that knowledge or general order of these skills in a specific discipline.

Our research is mainly focused on this problem by providing a hand, a situation analysis based on practical experiences in Morocco, and affecting the integration of new technologies for education and training, and other hand, the presentation of a distance learning platform, bringing in an electronic environment and intelligent stakeholders, namely, trainers, coaches, learners, tutors, and mentors.

Teachers, students and administrative framework are called continually to make and exchange services. To structure the information flow we modeled a significant information system based on ergonomic design university. The product of our work is a computing device, has solved several constraints. We also conducted its assessment by measuring the impact of its use.

The integration of new technologies for education is no longer an alternative; it has become an obligation and even guidance to develop these knowledge-sided. Today we share this work in order to present our experience and outlining the results, and also to examine the tracks that will follow to advance the science of modeling and engineering of learning ergonomics.
\end{abstract}

Keywords-Computing environments, library, ILS, learning activities, ICT

\section{$1 \quad$ Introduction}

The education and training in Morocco is subject to several factors that encourage continually to reviewing teaching approaches methods redesigned according to present needs and identified constraints. Universities that are open to virtual learning environment rapidly understood that beyond the use of computer tools and making the 
availability of practitioners and the various technologies of information and communication, they must create an identity by making digital a methodological framework for these pedagogies and a new direction to address problems that were generally survived without added value, due to lack of resources or specific or leading methodologies. The experience of digital workspaces in Moroccan universities is an operational approach that is being set up progressively; its spaces provide access to a set of tools and services specific to user profile.

From the described context, we thought to make a digital workspace that could help students learn and manipulate computer tools in a focused and rational way. Our experience was at the documentary service of FSBM - University Hassan II of Casablanca. The objective was to implement an online library where students have access to their research and could develop their methodologies scenarios adopted in platform ergonomically practical and constructive.

Libraries structures have known a continuous evolution since the introduction of the classification scheme of knowledge by Melvin Dewey in 1876. Libraries are constantly innovating to better serve their users and respond more adequately to the identified needs, taking into account the dimension of education engineering and research methodology as evocative; the creation of Carnegie libraries for instance, as a public library in 1879 , the development of cataloging code and later online catalogs. The emergence of digital libraries and virtual libraries marked a big change in the life of the book and documentary research. A change sometimes judged harshly but undoubtedly useful and effective for a broad orientation of users.

To enable a scientific and methodological framing of the addressed issues, we started from the launching questionnaire:

- What is the current status of the use of ICT and its practical contribution to the library of the Faculty of Sciences Ben M'Sik (FSBM)?

- What are the strategies adopted to ensure successful integration and suitable tools and ICT?

- What are the means and necessary steps to be taken to meet needs of our three main users of electronic library: teachers, students and administrative staff?

Since its inception in 1984, FSBM put into practice processes relating to the retrieval and librarians classic strategies. On the other hand, as innovations in new technologies emerge, FSBM has continued to procure and equip all its premises by new technologies covering laboratories, hands halls, amphitheaters, Tutorial rooms, administrative offices. [1]

The library of FSBM is limping to track all these mass changes in material resources and speed. It was not until 2008 that new areas have been developed to assist students, teachers and administrators to follow the path of ICT, and by creating more opportunities for learning and use of digital space, a cyberspace providing access to internet (free for students), space research, space equipped for film documentaries and conferences and a space saver for teachers and lecturers from where its nomination "The Media library."

And it is then that there has been the integration of better and more responsive tools; it is "FSBIBLIO", which is an management integrated system of library as an 
ICT meeting best to the library environment and to different information flows and exchanged requests.

\section{Study of Existing}

The library of the FSBM consists of two units: a library for students and teachers and a library of teacher-researchers. These two libraries use management software like Microsoft Access, an application for easy management inputs.

For managing loan books for teachers and administrative staff, a register loan is used where there is the title of the book borrowed, its inventory number, full name of the teacher, date of the loan and finally the signature of the borrower. For students who are seeking information, they must go through plugs catalog to choose a book, then fill out a loan. Note that the acquisition of the student identity card is sufficient to return the book.

Thus, students are forced to spend quite a lot of time in search of information about a book in the catalog records. Reference books that are not of great importance as an information have limited recorded data such as, (the title of the book, author, year of publication, bibliography), and sometimes they are torn or no longer readable or inexistent, which makes the book invisible and unavailable by situational strength, despite its physical existence in the library.

Librarians, meanwhile, spend a lot of time in information processing which is an essential process for library management. "It is the intellectual and physical treatment of all kinds of documents. Material processing of information covers all stages of receipt, verification and registration of the document. The intellectual processing of the document consists of a sequence of operations that allow identifying "identity" of the document, cataloging, creation of a classification plan by means of a classification. "[2]

In addition to intellectual processing, in our case, librarians create inventory numbers, type references for each entry and not copy mother records in Access database. Thereafter, plugs catalog are created, perforated and classified in drawers in alphabetical order and discipline, which are available locally before putting copies available to borrowers.

For professors who have direct access to library, they always have to come to the library for availability of books they are looking for.

\section{FSBIBLIO Project Implementation}

Before starting this project, a study in FSBM on needs expressed by various users of this domain (documentary service), three criteria were identified that seem essential, and that we must comply to conduct such work, namely:

- Ergonomics of digital space to achieve.

- Ease and flexibility of its use.

- Remote access to different types of information about books. 


\subsection{Document content}

Choosing software: An Integrated Library Management System (ILS) is a software package for computer management tasks of the library. Its various functions range from management's current loan statistics, to procurement management and revenue through the ongoing management of funds. A ILS is designed to automate the librarian cataloging, catalog management, procurement management (suggesting readers, pre-ordering, pre-cataloging, order tracking) and documents traffic management (loan, returns, reservations, late recovery of users). The ILS also allows access to a pool of records produced by a central library or shared by several libraries and this thanks to Z39.50. Standard [3]

It is through forums and articles dealing with this issue, and with the support of major studies by Patrice Chalon and Pascale Melon free on ILS that we could refine our research fields, and that our choice was explicitly focused on PMB software that meets the standards of an ILS and we felt met our needs.

"A research investigation was conducted to identify free ILS in at least 12 cases that provided criteria for selecting an ILS, 4-mentioned features. Five compared Koha and PMB, a compared Koha, Evergreen and PMB. [...]

PMB and KOHA ILS are indeed complete: they have the basic modules but also provide additional functionality, PMB is in this respect better off than KOHA, with particular participatory features (comments, add keywords tag also called free -ging).

EVERGREEN and OBIBLIO have only the catalog modules, circulation and OPAC. EVERGREEN development is new and very dynamic; the development schedule (ROAD-MAP) indicates the supply of modules and periodicals acquisitions for 2008. By cons, OBIBLIO has not undergone major changes since 2006 [4]

The ILS (PMB) which complies with the rules of the librarianship: it obeys the Z39.50 standards, manages the UNIMARC cataloging format and format records exchange ISO 2709. It also includes the XML data format in addition; its implantation in a digital work environment (DWE) is quite feasible because it offers innovative features including highly oriented Web 2.0.

Collection and data import: Before the retrieval of the Microsoft Access database, fields that were empty or did not exist were completed and cleared, because users did not capture all the information about books, but only that which is necessary to create catalog files. And with the collaboration of student affairs and human resources, data on drives could be recovered in various formats, which require more work to complete our project on time.

After this phase, which lasted about two months, we have imported an Excel file from the base then we have established a correspondence between the fields in UNIMARC and column numbers in Excel params.xml configuration file, then convert the file into format. csv. Then in ILS, text file was converted in UNIMARC iso 2709 and finally the Eureka phase, launching import records.

After importing records and their copies, a test of the quality of the migrated data was performed and made corrections to the problems encountered during the import, then the enrichment of records by key data such as keywords and the abstracts. And to take advantage of the functionality "loan / return" (traffic), we performed the import 
of different borrowers ie administrative staff, professors then students of FSBM, these data were imported in the database system import "Belgium" which is an advantage which is that the import of borrowers is made in group.

For theses and dissertations we had treated only theses during the last five years since they do not need an ISBN knowing that a documentary treatment should take place in two phases, the phase of cataloging and that of content analysis or indexing.

- Cataloguing was to develop the physical description of documents according to the UNIMARC format proposed by PMB.

- As for indexing, it was to characterize the content of documents. It is located on two levels: the classification and description.

The online launch of a thesis is made with the consent of the author.

Staff training: It is during the implementation stage of the project that the library service staff participated in practical training to develop their skills and subsequently, to ensure the proper functioning of the new ILS, while familiarizing them during test period which is to make simulations for adding new records, accounts borrowers, bibliographic records research, management of loans and delays, as well as other tasks that the software allows.

\subsection{Getting started}

The public interface of the catalog is usually called" Online Public Access Catalog" (OPAC). This interface makes the entire catalogs of the collections of the Faculty simultaneously available to all users of the library. Catalogs are accessible outside the walls of the library through the web.

Evidence on the results: For students and professors, time is no longer an obstacle as the remote access to library catalogs is made beyond the walls of library. This advantage gave students the opportunity to easily find what they are looking for because the interface allows advanced search criteria field and, moreover the records content is being enriched (abstracts, tables of contents, etc.). Other benefit is that they can book the book after consulting its location. Longer need to come to the library just to find out whether a particular book is available.

As librarians, to our pleasant surprise, they have become real experts (even computer users), they are highly motivated and anticipating their learning and the expertise required. The transformation of traditional ways to the era of computerization, many have encouraged and guided to learn and document more. Among the advantages gained for librarians, they are no longer forced to make prints (sheets, catalogs, card lending, letter of complaint to delays reminder etc.) because everything happens in an automatic way, and well as new tasks have emerged (the upgrade notices, research, research and adding links to online resources) that demonstrates an evolution rather to maintain and improve. Another advantage, saving time for typing copies, a transaction that was previously a heavy obligation to maintain the archive and full traceability, with elimination of repetitive tasks without added value (intercalation sheets cataloging classification of forms of loans, statistical manual etc.). Cata- 
loging and indexing have become more rigorous and faster, statistics becoming more comprehensive, faster and reliable.

\section{Conclusion}

The evolution of the library of FSBM from its traditional activities until the advent of digital has been the starting point for our work, which allowed us to enter the abstract of computerization of the process of library management, starting up conventional procedures to the extent of providing an ergonomically appropriate platform that is responsive to the substantial needs. Planted on an electronic and intelligent space, we looked at the practice and easiness in use proposed by the product, and that either for the students or professor, or administrative Staff. Among our most visible results, the multiplied increase on the use of the library, as well as loans application books. For Librarians, management is made without constraints of synchronous attendance, and management can be done day long according to the chosen optimal rhythm.

The integration of new technologies of information and communication in the process of teaching and learning can be taken from several issues. Our work has resulted in one hand, a dialog of the virtual in a reality environment, and it is often at this stage that communication may be failing or successful. On the other hand, the integration of stakeholders in the university community, to compete in this project has allowed us to better define the need and focus on the real steps to take and the best methodologies to provide for users of ICT. Student perceived as passive actor, must fully integrate its synergistic role and engage and interact. "We move from a formal search mode to plasticity of navigation" [5]

\section{$5 \quad$ References}

[1]. Touri Bouzekri 2012 Language Prerequisites, Teaching Language and Employment Market Requirements, MESCE 2012, Tunis.

[2]. Pascal Mouhoulo \& Marien Ngouabi 2003 De la bibliothèque manuelle à la bibliothèque hybride: cas du Centre de Documentation de l'OMS/AFRO https://www.memoireonline.com/12/07/754/bibliotheque-manuelle-hybridecentre-documentation-oms-afro.html

[3]. Pierre Angulaire 2006 Integrated Library Management System (ILS) the document information system for better visibility of resources. https://www.imist.ma/images/stories/lettres/lettre_IMIST\%20N\%B07.pdf (page2).

[4]. Patrice Chalon and Pascale Mélon 2008 ILS in Belgium: current situation and analysis http://eprints.rclis.org/12157/

[5]. Link-Pezet J. Mass training to electronic information tools. BBF 40 No. 5, http://bbf.enssib.fr/consulter/bbf-1995-05-0035-002 


\section{Authors}

Mohssine Bentaib is PhD student working at the Faculty of Sciences ben m'sik Hassan II University of Casablanca Morocco, in charge of the information systems department.

Mohammed Talbi is Professor at Faculty of sciences Ben M'sik university Hassan II of Casablanca, Morocco, director of Observatory of Research in Didactics and University Pedagogy.

Bouzekri Touri is Associate Professor at Faculty of sciences Ben M'sik university Hassan II of Casablanca, Morocco. He is heading LAPSTICE Lab and does research in Science Education, communication sciences and disorders and school psychology.

Article submitted 06 August 2018. Resubmitted 23 October 2018. Final acceptance 27 October 2018. Final version published as submitted by the authors. 